\title{
A influência nos parâmetros de usinagem da matriz endurecida no processo e no custo de produção da camisa de corte polipropileno
}

Tony Denis da Silva detidealmeida@gmail.com Faculdade de Tecnologia (CETEP), Curitiba, PR, Brasil

Gleison Hidalgo Martins

Gleisonhidalgo@gmail.com Universidade Federa
Curitiba, PR, Brasil

\begin{abstract}
RESUMO
O processo de retífica cilíndrica convencional é lento e eleva os custos de produção dos mais variados componentes. Por este motivo, diversas pesquisas têm sido realizadas sobre a usinagem em materiais temperados. O estudo da pesquisa focou na avaliação do método atual de usinagem convencional e nos insertos da classe CBN (nitreto cúbico de bório) em peças de geometria estáveis, para propor alternativas na redução no tempo de processamento, no custo de usinagem e no erro de circularidade camisa de corte de chapa de polipropileno. A metodologia empregada por experimento em chão de fábrica apresentou resultados positivos com o projeto piloto, o qual proporcional a redução no tempo total de processamento, apresentou redução no custo de produção bem como manteve a estabilidade na tolerância do erro de circularidade camisa de corte de chapa de polipropileno.
\end{abstract}

PALAVRAS-CHAVE: Camisa de corte. Chapa de polipropileno. Erro de circularidade. 


\section{INTRODUÇÃO}

Este trabalho está direcionado para a otimização de um processo de usinagem convencional do componente da camisa de corte de chapa de polipropileno utilizado no processo de termoformagem.

Conforme mensurado na produção da camisa de corte o tempo médio no processamento das peças são 25 horas no torno CNC (Comando Numérico Computadorizado), 6 horas na retífica plana e 85 horas retifica cilíndrica.

O ponto crítico observado na coleta de dados do processo está no tempo do processamento retifica cilíndrica somando 116 horas, etapa a qual se leva 85 horas.

Com o alto tempo do processamento da usinagem do componente da camisa de corte de chapa de polipropileno em função do processo de retífica cilíndrica ser convencional, torna esta etapa trabalhosa incidindo em um alto custo de produção.

O estudo da pesquisa focou na avaliação do método atual de usinagem convencional e nos insertos da classe CBN (nitreto cúbico de bório) em peças de geometria estáveis e propor alternativas na redução no tempo de processamento, no custo de usinagem e no erro de circularidade camisa de corte de chapa de polipropileno. Para tanto define-se os objetivos específicos para o cumprimento do objetivos geral:

$\checkmark$ Desenvolver a revisão de Literatura;

$\checkmark$ Elaborar informações do processo de produção;

$\checkmark$ Desenvolver dispositivo para fixação da peça a ser usinada;

$\checkmark$ Elaborar parâmetros de corte para o processo;

$\checkmark$ Garantir requisitos mínimos de projeto para aplicação da peça usinada;

A pesquisa será realizada através análise de dois processos, um no processo atual com as devidas usinagens e o outro por experimento, o qual representa o melhor exemplo de pesquisa cientifica, para teste de hipóteses, que estabelecem relações entre causa e efeito entre variáveis. Essencialmente, pesquisa experimental consiste em determinar um objeto de estudo. Desta forma será realizado o levantamento abrangendo os resultados e as conclusões obtidas a partir deste estudo.

\section{REVISÃO DE LITERATURA}

\section{PROCESSO DE USINAGEM CONVENCINAL}

Segundo Ferraresi (1977) o conceito de usinagem está no fato em que uma ferramenta de corte, desbasta o material gerando cavaco para obter uma peça metálica ou não, conferindo a forma, a dimensão e o acabamento.

O processo de torneamento é um tipo de processo convencional de usinagem que utiliza ferramentas com geometria definida, destinada à obtenção de superfícies por revolução com o auxílio de uma ou mais ferramentas monocortantes (FERRARESI, 1977). 
De Acordo com Diniz (2010) existem dois itens que influenciam diretamente na qualidade do processo e na qualidade dimensional da peça: a geometria da aresta de corte e os parâmetros de corte empregados no processo apresentadas da seguinte maneira:

- Velocidade de corte $\left(V_{c}\right)$ : define como sendo a velocidade tangencial instantânea resultante da rotação da ferramenta em torno da peça; unidade (m/min);

- Avanço de corte (f): é a distância entre duas superfícies consecutivas em usinagem, medida no plano de trabalho perpendicular à direção de corte ilustrada pela Figura 1 em outras palavras é o movimento da ferramenta gerado manualmente ou pela máquina que tem como objetivo provocar um deslocamento entre a peça e a ferramenta; unidade $(\mathrm{mm} /$ rotação);

- Profundidade de corte $\left(a_{p}\right)$ : é a espessura ou profundidade de penetração medida perpendicularmente ao plano de trabalho da peça; (unidade $\mathrm{mm}$ ).

As direções dos movimentos de corte, de avanço e de efetivo, bem como os ângulos da direção de avanço, da direção efetiva e o plano de trabalho são ilustrados na Figura 1.

Figura 1: Representação dos vetores de torneamento

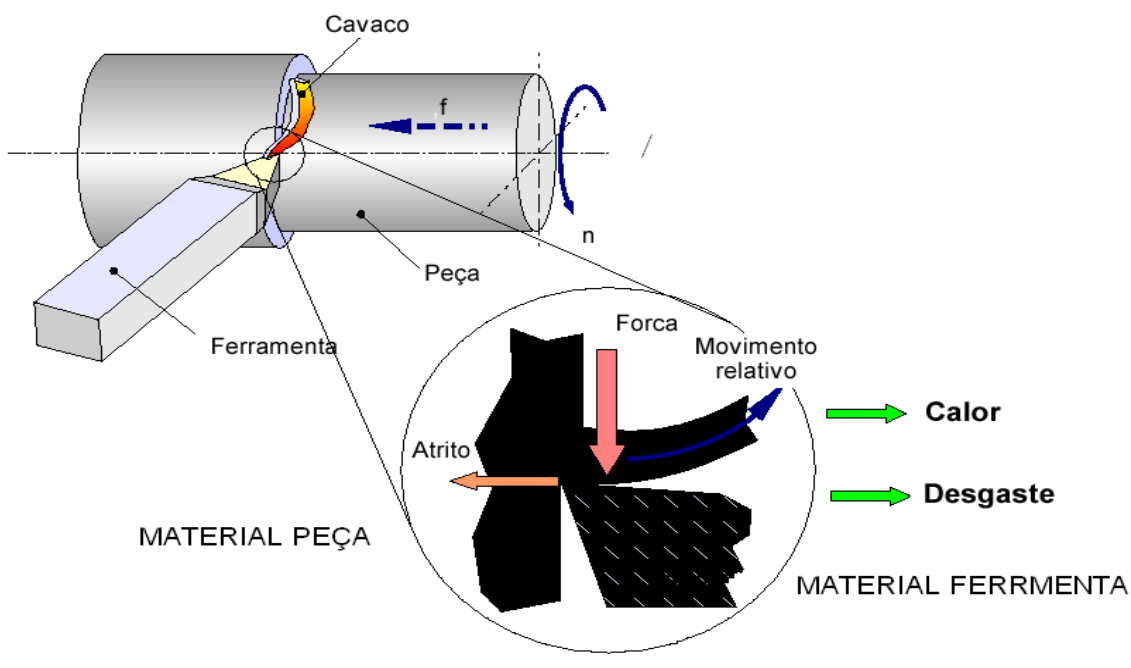

Fonte:Diniz, (2010)

No processo de usinagem é preciso definir algumas superfícies de trabalho, segundo (DINIZ, 2010) essas superfícies são divididas em três de acordo com a Figura 2.

- Superfície a Usinar: superfície da peça antes da operação de usinagem;

- Superficie em usinagem: aquela que está sendo gerada pela ferramenta. Ter-se-á a superfície em usinagem principal ou secundária quando a geração da mesma estiver ocorrendo pela ação de aresta principal de corte, respectivamente.

- Superficie usinada: face que foi gerada pelo processo de usinagem. 
Figura 2: Superfícies de trabalho

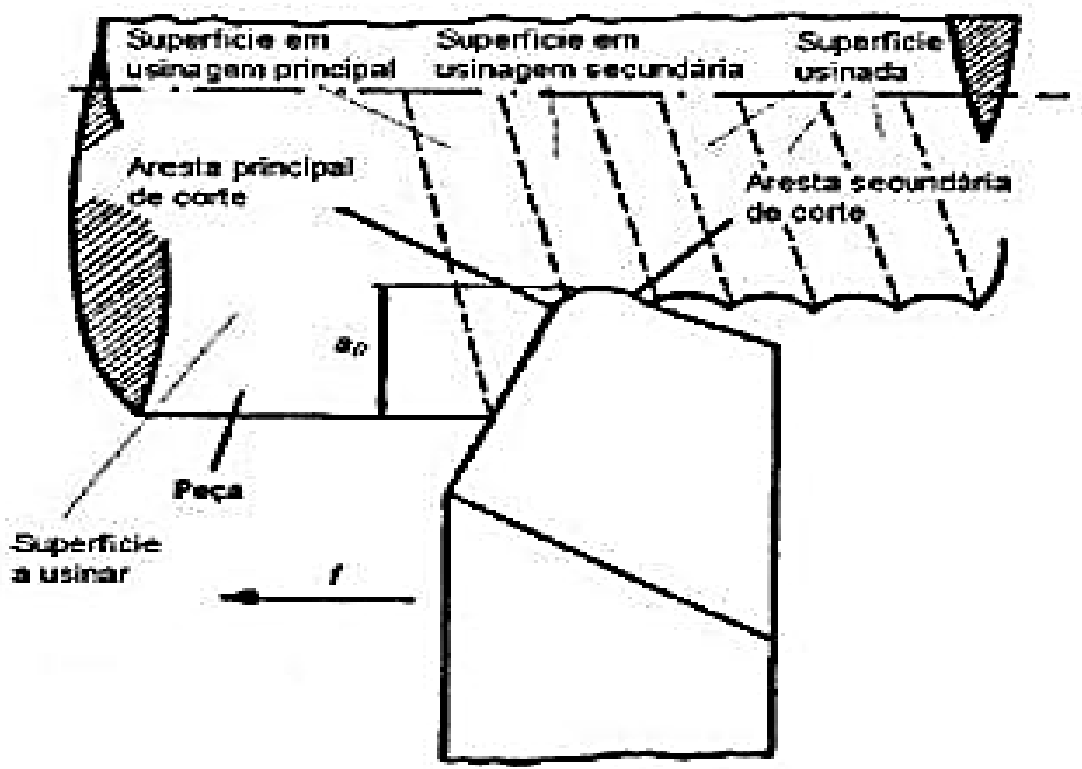

Fonte: Diniz, (2010)

Conforme Figura 3 alguns pontos em que a geometria de ferramenta influencia diretamente na qualidade do processo é importante definir alguns ângulos e arestas da ferramenta (DINIZ, 2010).

- Superfície de saída (Ay): Superfície que tem por função fazer o cavaco escoar;

- Superfície secundária de corte $\left(S^{\prime}\right)$ : gera quando é utilizada uma superfície secundária na peça;

- Superfície secundária de folga $\left(A^{\prime} a\right)$ : contém a aresta secundária e defronta com a superfície em usinagem secundária;

- Superfície principal de folga $(\mathrm{A} a)$ : é a superfície que defronta com a usinagem;

- Aresta principal de corte (S): formada pela interseção das superfícies de folga e saída;

- Ponta de corte: é a ponta responsável pelo corte, formada pelo encontro entre a superfície principal, a secundária e a de folga. Normalmente existe um raio de arredondamento. 
Figura 3: Geometria da ferramenta de corte

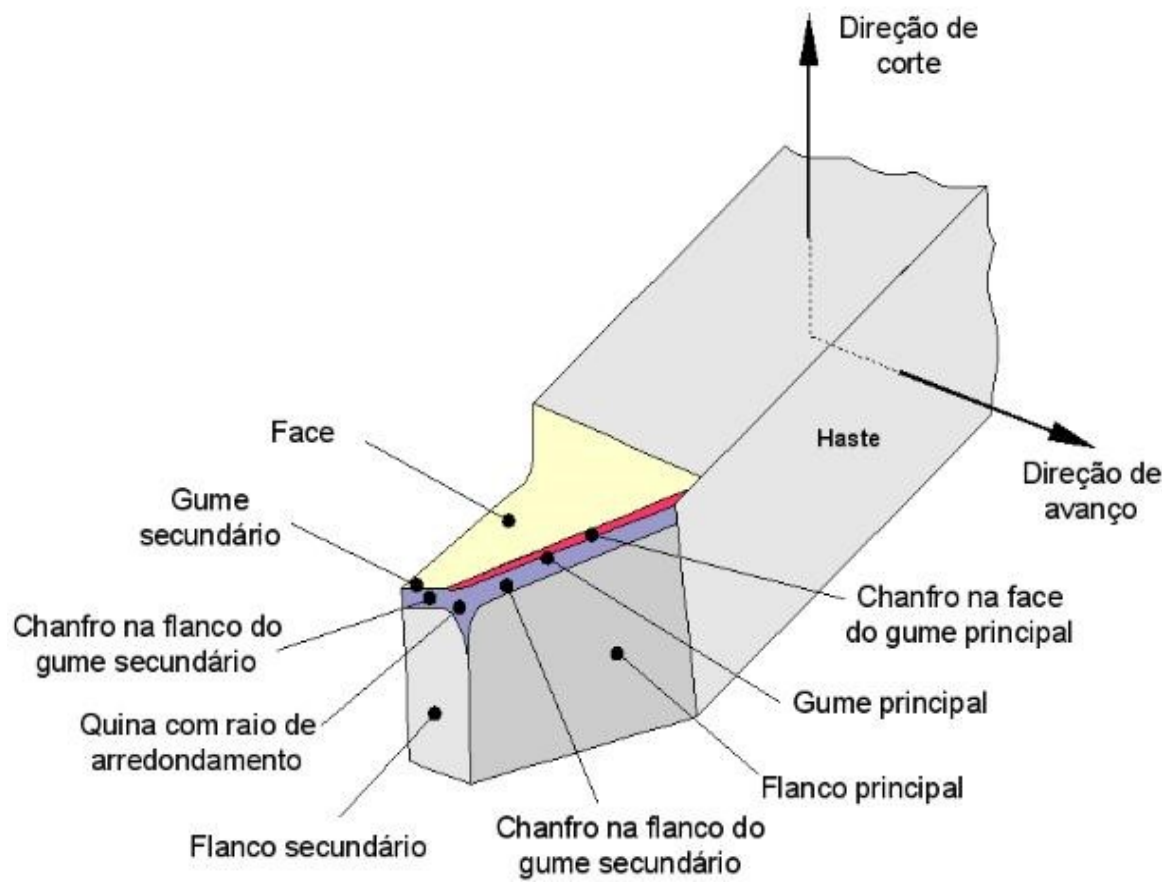

Fonte: Diniz, (2010)

Para Souza (2004) existem diversas variáveis no processo de torneamento e algumas são variáveis de entrada e saída, conforme mostra a Figura 4. As propriedades mecânicas, físicas e químicas do material da peça a ser usinada são de extrema importância no processo de usinagem.

Figura 4: Relações de entrada e saída no torneamento

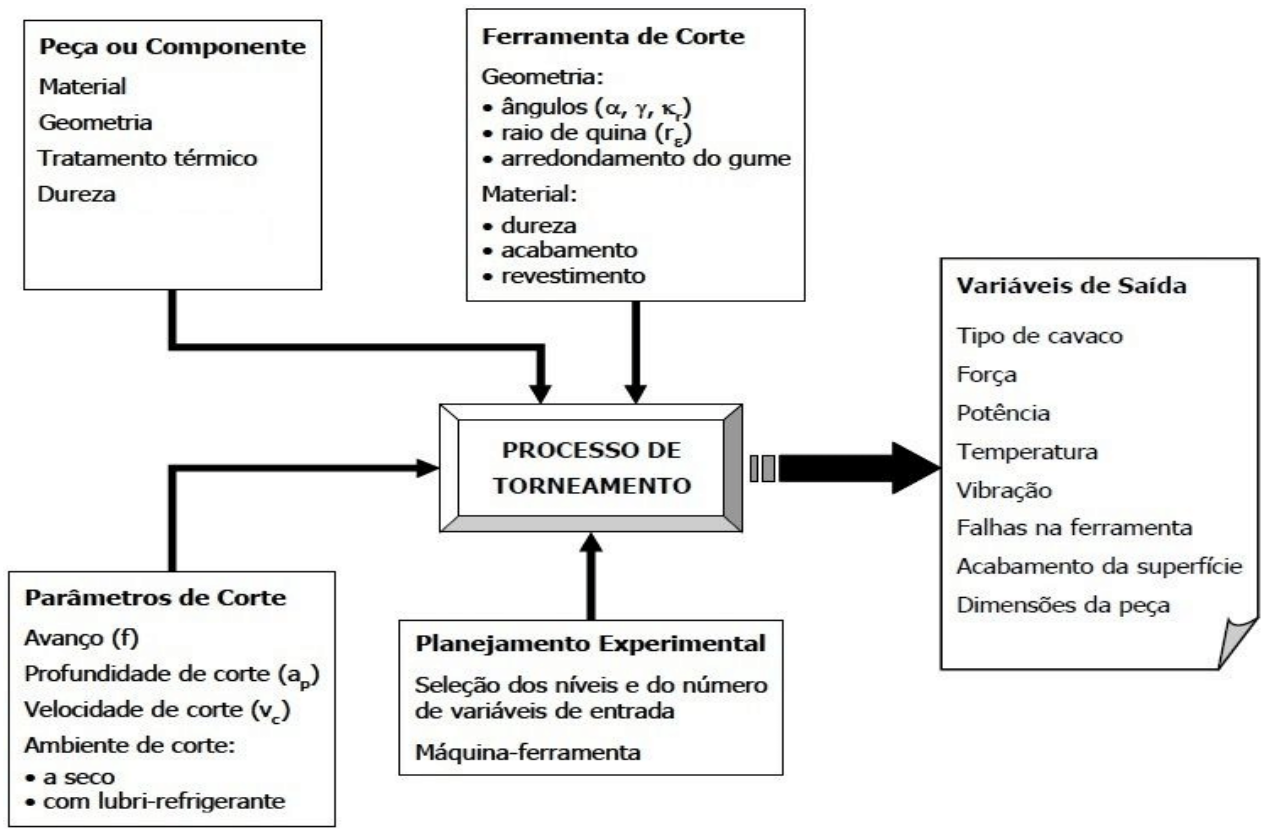

Fonte: Adaptado de Black, (1994) 


\section{GEOMETRIA DAS PEÇAS}

A geometria da peça varia de acordo com a aplicação. Para Souza (2004) os parâmetros como profundidade de corte $\left(a_{p}\right)$ e avanço $(f)$ devem ser levados em consideração. Um eixo esbelto ou peças com pequenas espessuras podem sofrer vibração durante o processo de usinagem conforme ilustrados pela as Figura 5 .

Figura 5: Geometria da peça

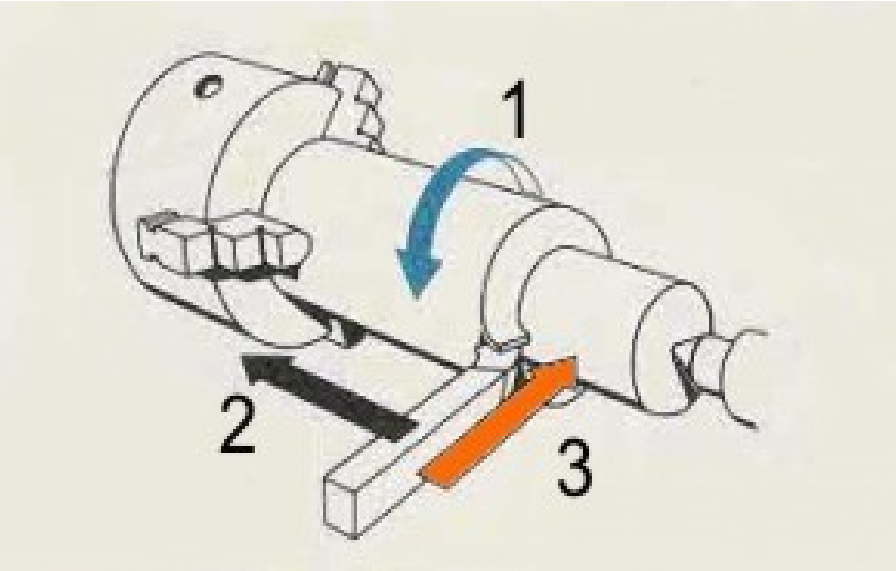

1 - Rotação da peça - corte

2 - Translação da ferramenta - avanço

3 - Transversal da ferramenta - profundidade

Fonte: Autor, (2016)

\section{ÂNGULOS DE TRABALHO}

Nas palavras de Ferraresi (1970) o ângulo de trabalho são os ângulos entre a ferramenta e a peça conforme Figuras 6,7 e 8, que dependem não somente do formato da ferramenta como também da sua posição relativa a peça.

Segundo Borges (2017) a principal característica que uma ferramenta de corte deve apresentar é a dureza a quente. Para trabalhar metais, os principais materiais usados são os aços especiais, o aço rápido e o metal duro (numa escala crescente de dureza). Entretanto a maior dureza do metal duro é obtida em detrimento de sua tenacidade, resistindo menos a eventuais choques com a peça usinada.

Figura 6: Ângulos de corte I

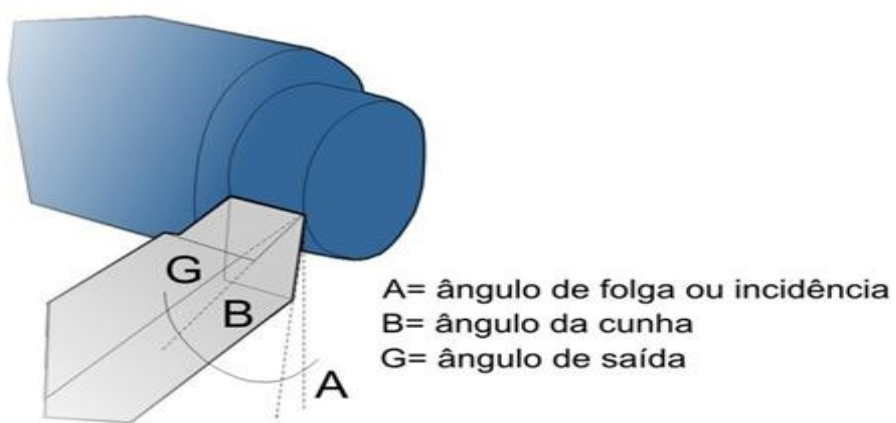

Fonte: Autor, (2016) 
Figura 7: Ângulos de corte II

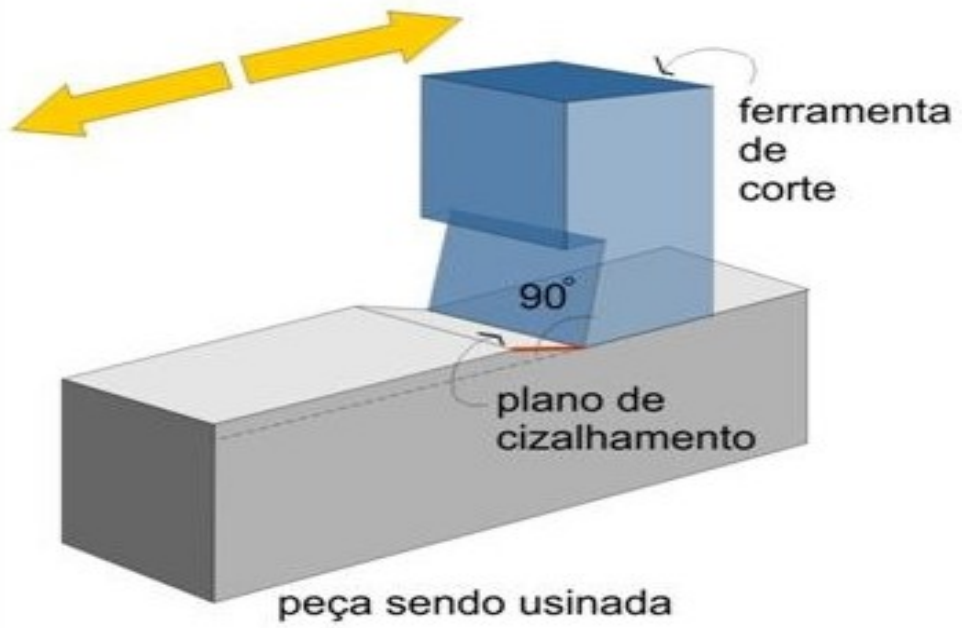

Fonte: Autor, ( 2016)

Figura 8: Ângulos de corte III

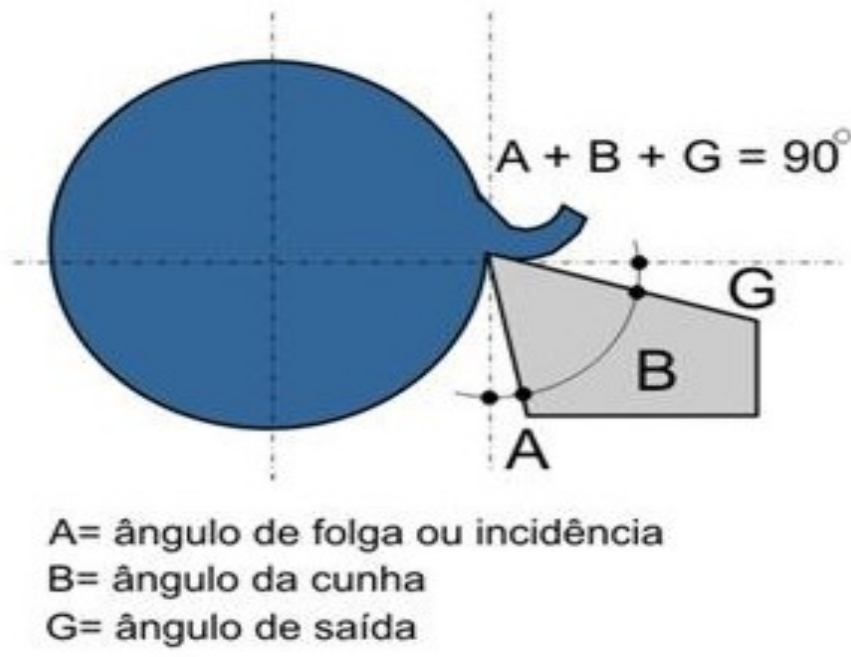

Fonte: Autor, (2016)

\section{GEOMETRIA DAS FERRAMENTAS}

A ferramenta deve ser usada apenas para o processo ao qual foi projetada, qualquer mudança na geometria ou material da peça podem alterar o seu desempenho, sendo necessário um novo estudo como relação aos seus ângulos. Tanto a formação de cavacos, os componentes da força de usinagem e o desgaste da ferramenta são influenciados pela geometria da ferramenta (DINIZ, 2010).

Já para Souza (2004) salienta que quanto maior o ângulo de saída $Y_{f}$ (Figura 9), menores serão a deformação e o trabalho de separação do cavaco da peça e, por consequência, menores serão: a temperatura, a pressão específica de corte e o desgaste da ferramenta. 
Figura 9: Ângulo de ferramenta de corte

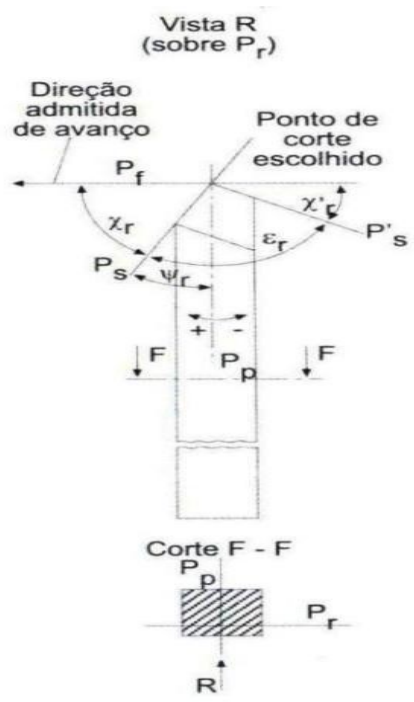

(a)

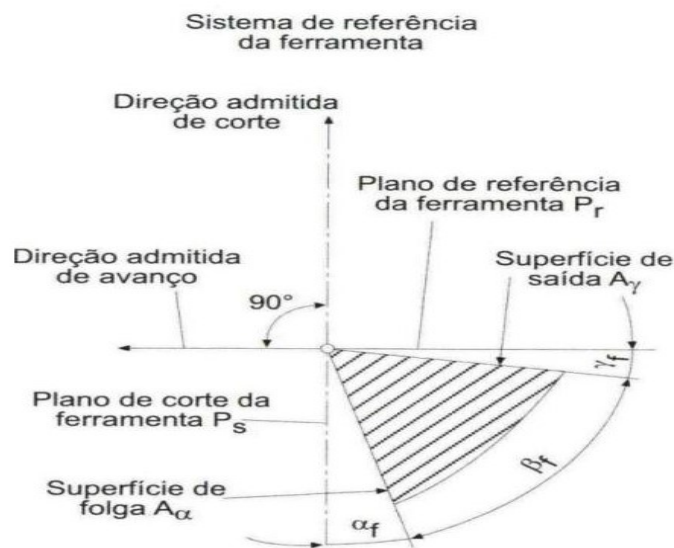

(b)

Fonte: Adaptado de Diniz, (2010)

Sabe-se que com o aumento do ângulo de saída o gume da ferramenta torna-se mais frágil e passível de quebra. Ao usinar materiais dúcteis o ângulo de saída tende a ser positivo, fazendo com que o cavaco escoe sobre a superfície de saída da ferramenta. Já em materiais frágeis o ângulo tende a ser ao contrário, ou seja, negativo, fazendo com que haja a quebra do cavaco. Com a utilização do ângulo de saída negativo forças de corte são maiores e consequentemente potencializa o corte (DINIZ, 2010).

\section{PARÂMETROS DE CORTE E FERRAMENTAS DE USINAGENS}

Para que o processo de usinagem ocorra é necessário que os parâmetros de corte sejam ajustados para que se tenha a melhor relação de recalque bem como o menor tempo de usinagem, acabamento especificado e o menor desgaste da ferramenta. A velocidade de corte $(\mathrm{Vc})$, avanço (f) e a profundidade de corte $\left(\mathrm{a}_{\mathrm{p}}\right)$ devem ser estabelecidos conforme o tipo de material, a geometria da peça e o tipo de fixação na placa do torno (DINIZ, 2010).

O material de ferramenta influencia o processo significativamente, segundo (STEMMER, 2007) algumas características devem ser levadas em consideração.

- $\quad$ Elevada dureza a frio, superior à peça a ser usinada;

- $\quad$ Elevada dureza a quente;

- $\quad$ Estabilidade química;

- $\quad$ Facilidade de obtenção a preços econômicos;

- $\quad$ Resistência a abrasão;

- Tenacidade para resistir a grandes esforços de corte e impactos.

Os tipos de materiais são:

- Aços ferramentas;

- Aços rápidos comuns;

- $\quad$ Aços rápidos com cobalto;

- $\quad$ Carbonetos sintetizados (Material duro-MD);

- $\quad$ Cerâmica; 
- $\quad$ Nitreto cubico de boro (CBN);

- $\quad$ Diamante.

\section{PROCEDIMENTOS METODOLÓGICOS}

\section{AMBIENTE DE PESQUISA}

A "Indústria de embalagens" é uma das maiores empresa multi packaging da América Latina e atua nos segmentos de embalagens rígidas, semirrígidas, flexíveis, laminados e rótulos. Entre os mercados atendidos pela companhia estão alimentos, bebidas, cosméticos, farmacêuticos, higiene pessoal, limpeza doméstica, médico-hospitalares e fast food. Atualmente, a empresa conta com mais de sete mil funcionários, que atuam nas plantas do Brasil, Argentina, Chile, Uruguai e México.

A divisão de rígidos da América Latina, que processam cerca de 10.000 toneladas de polímeros ao mês, somente a unidade Paraná é responsável pela transformação de 1.300 toneladas ao mês. No processo de termoformagem ao qual é o foco deste trabalho, são 32 termoformadoras que transformam 500 toneladas ao mês. A principal matéria prima utilizada é o polipropileno, armazenado em silos e enviados as extrusoras por meio de tubo vias, evitando assim o contato com os operadores e por sua vez contaminação.

No setor de extrusão são processadas as bobinas que alimentam as termoformadoras. $O$ processo de termoformagem consiste em aquecer a chapa de polipropileno proveniente da bobina e transforma-la através de um molde a forma desejada. As principais linhas de produtos são para água, margarinas, doces e produtos de higiene.

\section{CARACTERIZAÇ̃̃O DA PESQUISA}

Segundo Gil (2002) o experimento representa o melhor exemplo de pesquisa cientifica, para teste de hipóteses que estabelecem relações entre causa e efeito entre variáveis. Essencialmente, pesquisa experimental consiste em determinar um objeto de estudo. De modo geral, o experimento representa o melhor exemplo de pesquisa científica. Essencialmente, a pesquisa experimental consiste em determinar um objeto de estudo, selecionar as variáveis que seriam capazes de influenciá-lo, definir as formas de controle e de observação dos efeitos que a variável produz no objeto.

O esquema básico da experimentação pode ser assim descrito: seja Z o fenômeno estudado, que em condições não experimentais se apresenta perante os fatores A, B, C e D. A primeira prova consiste em controlar cada um desses fatores, anulando sua influência, para observar o que ocorre com os restantes.

Quando os objetos em estudo são entidades físicas, tais como porções de líquidos, bactérias ou ratos, não se identificam grandes limitações quanto à possibilidade de experimentação. Quando, porém, se trata de experimentar com objetos sociais, ou seja, com pessoas, grupos ou instituições, as limitações tornam-se bastante evidentes. Considerações éticas e humanas impedem que a experimentação se faça eficientemente nas ciências humanas, razão pela qual os procedimentos experimentais se mostram adequados apenas a um reduzido número de situações. 
Todavia, são cada vez mais frequentes experimentos nas ciências humanas, sobretudo na psicologia. A pesquisa experimental constitui o delineamento mais prestigiado nos meios científicos. Consiste, essencialmente em determinar um objeto de estudo, selecionar as variáveis capazes de influenciá-lo e definir as formas de controle e de observação dos efeitos que a variável, produz no objeto. Trata-se, portanto, de uma pesquisa em que o pesquisador é um agente ativo, e não um observador passivo.

\section{DELINEAMENTO DA PESQUISA EXPERIMENTAL}

Para a pesquisa foram envolvidos 2 operadores, um de retifica e outro de torno CNC. O operador de CNC, o qual tem maior participação nos resultados relatou as devidas alterações do processo, o recomendado e o realmente utilizado para viabilidade do estudo.

Dando início ao processo para pré-usinagem, foi utilizado um torno CNC modelo GU800, sendo utilizado para os ensaios de acabamento um torno CNC modelo Multiplic $35 \mathrm{~d}$.

No processo de usinagem, seguiram-se as etapas de fabricação:

- $\quad$ Pré-usinagem para alívio de tensões;

- $\quad$ Tratamento térmico para alívio de tensões;

- $\quad$ Pré-usinagem pra a têmpera;

- $\quad$ Avaliação do erro de circularidade;

- Tratamento térmico para têmpera à vácuo;

- $\quad$ Avaliação do erro de circularidade;

- $\quad$ Retificação plana;

- Torneamento de acabamento;

- $\quad$ Avaliação do erro de circularidade;

- Retificação cilíndrica;

- $\quad$ Avaliação do erro de circularidade;

- Teste prático da peça usinada.

\section{ANÁLISE DE DADOS E RESULTADOS}

\section{INFORMAÇÕES DO PROCESSO DE PRODUÇÃO}

\section{Processo de termoformagem}

A termoformagem é um processo que consiste em moldar chapas plásticas dando forma ao produto através da utilização de calor e pressão tanto positivas como a vácuo. Os principais componentes do molde de termoformagem estão representados na Figura 10 e a Figura 11 ilustra o uma matriz real para melhor visualização do contexto. 
a) Prensa chapa responsável pela fixação da chapa de polímero;

b) Contra molde, o qual estira a chapa até o fundo extrator;

c) Camisa interna tem a finalidade de dar a forma ao produto final;

d) Fundo extrator do produto;

e) Faca de corte possui a função de cisalhar o produto;

f) Camisa de corte além de cisalhar o produto junto com a faca de corte, também remove calor da camisa interna.

Devido à espessura da chapa o processo exige folga máxima entre o conjunto de corte formado pela faca e a camisa, na ordem de 0,04 milímetros. A abrasão provocada pelo polímero desgasta o conjunto sendo necessária a dureza superficial entre 58 a 64 HRC (Escala de dureza Rockwell).

Figura 10 - Componente do molde de termoformagem

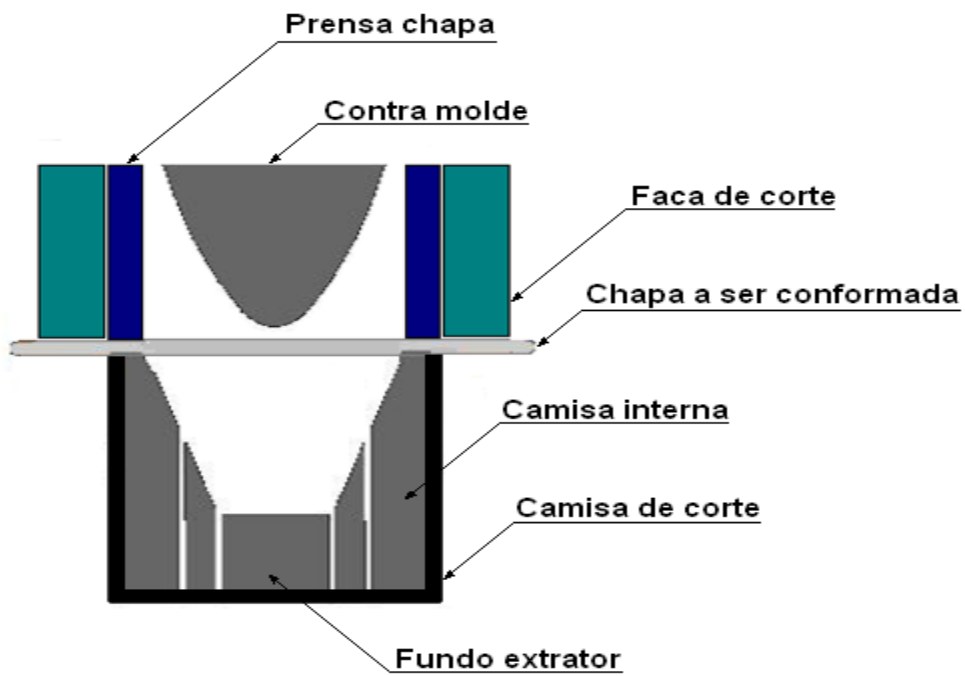

Fonte $-\mathrm{O}$ autor, (2016)

Figura 11 - Matriz de termoformagem

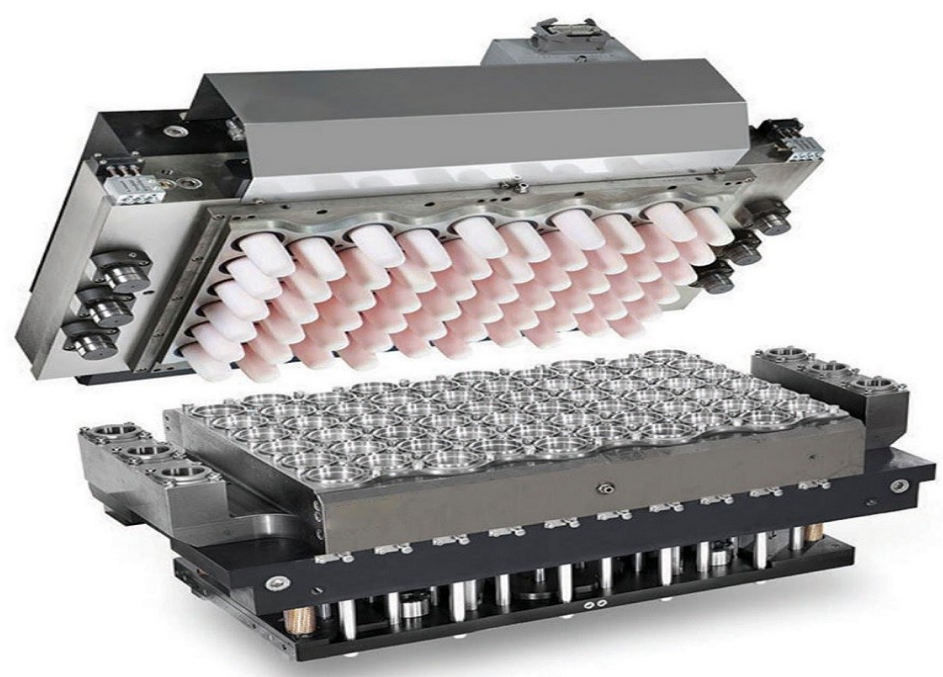

Fonte: Vegmetalúrgica, (2017) 
No processo de termoformagem são envolvidas basicamente sete etapas e é importante ressaltar que cada etapa é imprescindível na qualidade do produto final. Todas as fases do processo são esclarecidas na Figura 12, tais como:

- $\quad$ Aquecimento da chapa;

- $\quad$ Fixação da chapa pela prensa;

- $\quad$ Atuação do contra-molde para o estiramento;

- Vácuo para a formação do produto final;

- $\quad$ Corte efetuado pelo conjunto faca/camisa;

- $\quad$ Extração efetuada pelo fundo;

- $\quad$ Produto final.

Figura 12 - Processo de termoformagem

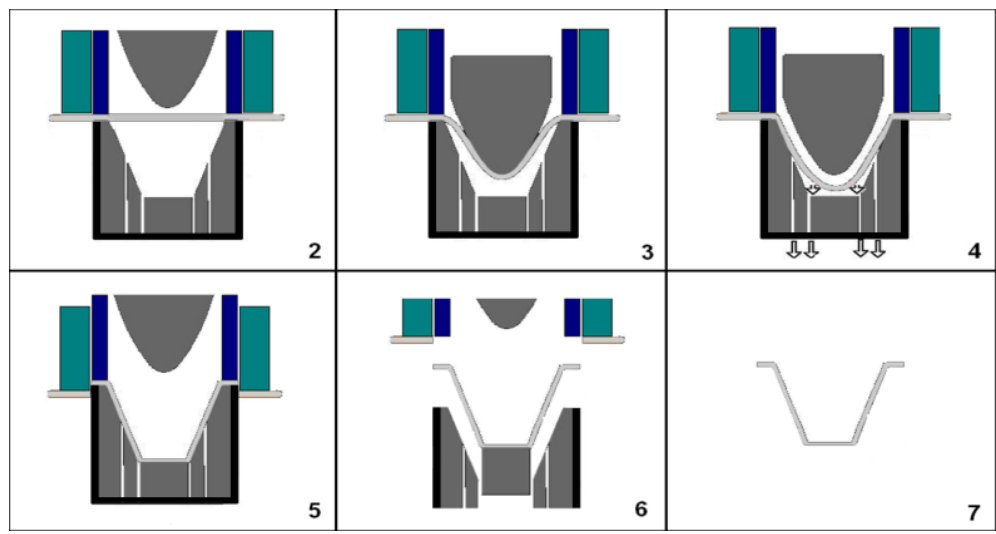

Fonte: o autor, (2016)

\section{Componente a ser usinado}

A peça a ser usinada é a "camisa de corte" de aço ABNT D2 com dureza entre 60 e $62 \mathrm{HRC}$ conforme a Figura 13. O processo atual de fabricação do componente consiste em:

$\checkmark \quad$ Torneamento de pré-usinagem para alívio de tensões;

$\checkmark \quad$ Torneamento de pré-usinagem para têmpera a vácuo;

$\checkmark \quad$ Torneamento de pré-usinagem para retífica;

$\checkmark \quad$ Retífica plana e cilíndrica.

A aplicação do componente não exige à retificação no perfil interno uma vez que é alojada a "camisa interna", desde que seja observando o erro de circularidade de 0,02 milímetros o processo torneamento. 
Figura 13 - Camisa de corte

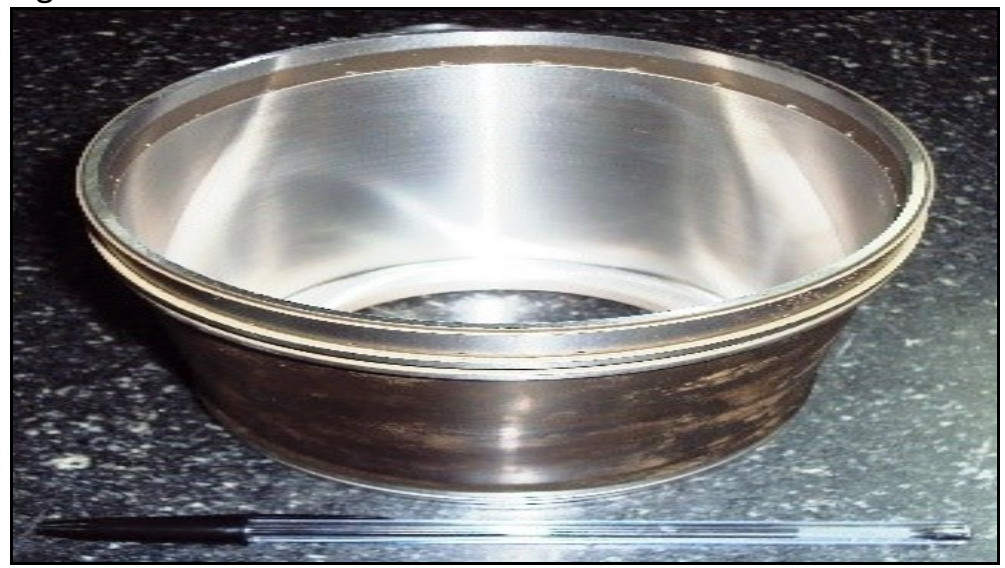

Fonte $-\mathrm{O}$ autor, (2016)

\section{PESQUISA DE EXPERIMENTO PILOTO}

\section{Equipamentos}

Para a pré-usinagem foi utilizado um torno CNC fabricado pela Index Traub, (Figura 14), modelo GU 800 com curso no eixo $X$ de $310 \mathrm{~mm}$ e no eixo $Z$ de $820 \mathrm{~mm}$.

A torre tem capacidade para 16 ferramentas e a potência nominal do motor é de $40 \mathrm{~kW}$ equipado com comando numérico Siemens.

Como os ensaios de acabamento não exigem grande potência foi utilizado um torno CNC fabricado pela Romi, (Figura 15) modelo Multiplic 35D com curso no eixo $X$ de $280 \mathrm{~mm}$ e $Z$ de $1500 \mathrm{~mm}$.

A torre tem capacidade para oito ferramentas e a potência nominal do motor principal é de $15 \mathrm{~kW}$ equipado com comando numérico Fanuc.

Figura 14 - Torno CNC Index GU 800

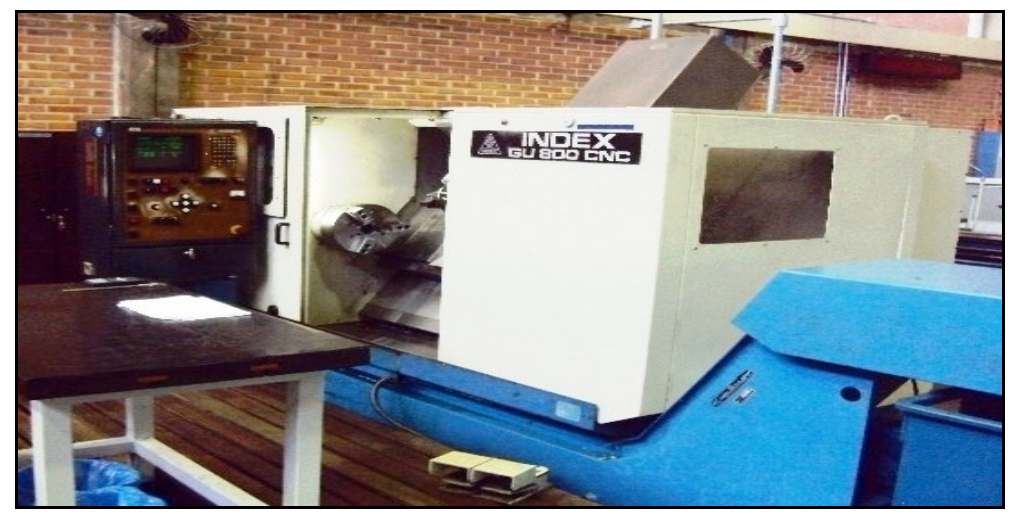

Fonte: o autor, (2016) 
Figura 15 - Torno CNC Romi Multiplic 35D

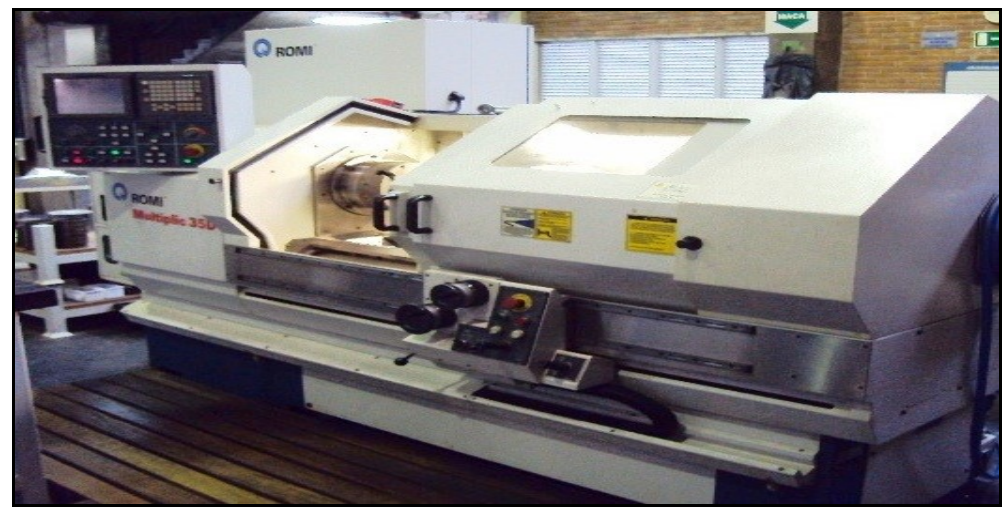

Fonte: o autor, (2016)

A aquisição de dados para o controle dimensional foi realizada utilizando uma máquina para medir as coordenadas, fabricado pela Mitutoyo, modelo B251 com incerteza de medição expandida $U=2,1+\mathrm{L} / 3000 \mu \mathrm{m}$. Figura 16.

Figura 16 - MMC Mitutoyo B-251

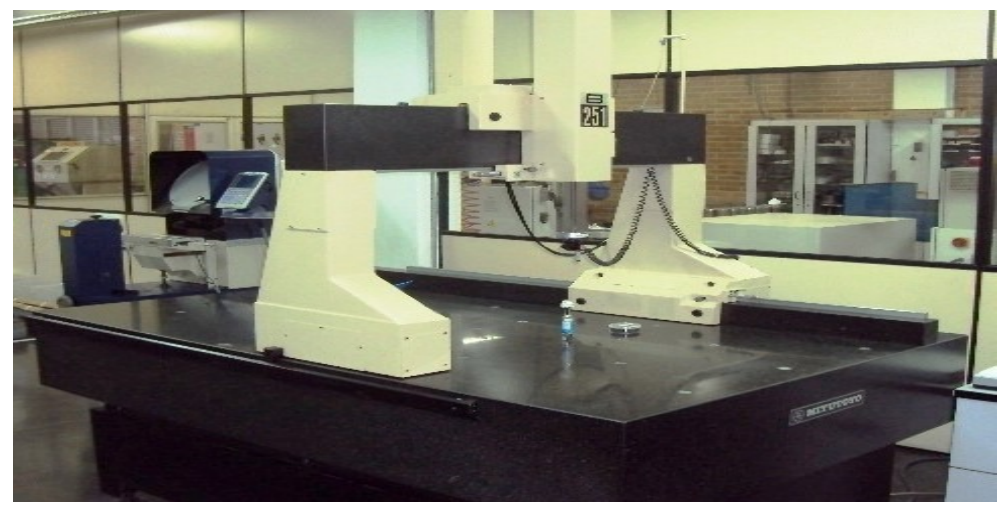

Fonte: o autor, (2016)

\section{PROCESSO DE USINAGEM}

A proposta para o novo processo de usinagem seguiu as etapas de fabricação ilustradas no fluxograma Figura 17. 
Figura 17 - Fluxograma do processo
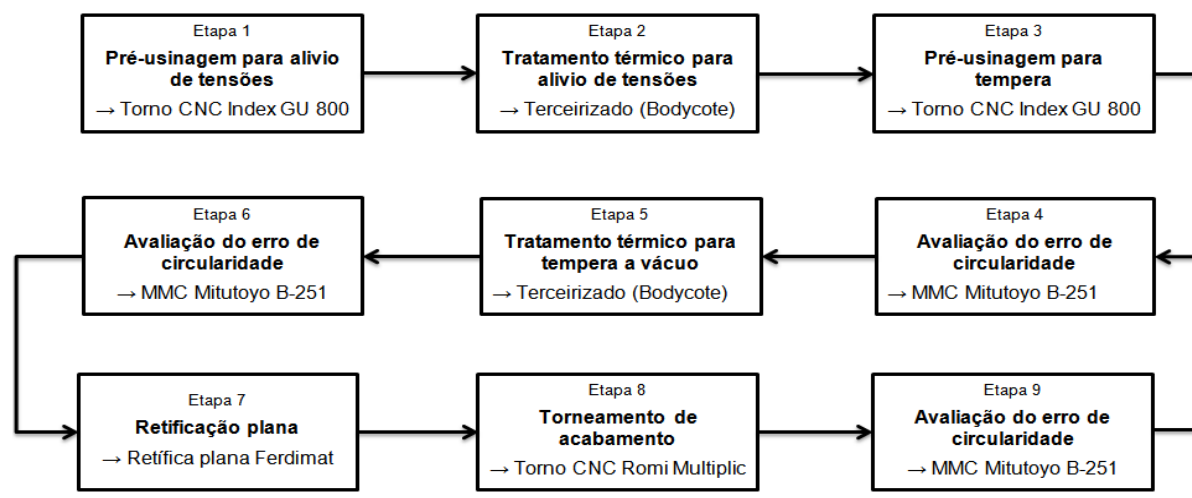

Etapa 4

Avaliação do erro de circularidade $\rightarrow$ MMC Mitutoyo B-251

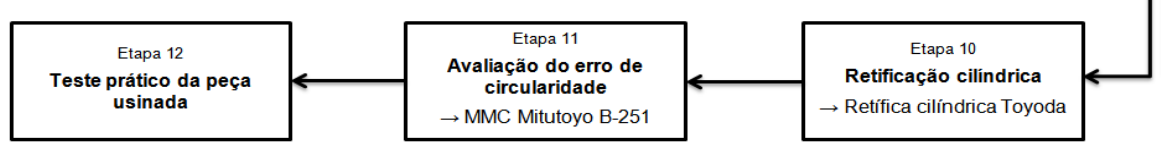

Fonte: o autor, (2016)

\section{PRÉ-USINAGEM PARA ALÍVIO DE TENSÃO}

A partir do aço ABNT D2 fornecido pela empresa homologada com dureza especificada pela "Indústria de Embalagens", as peças foram preparadas para o tratamento térmico de alivio de tensões de acordo com a Figura 18. O processo de alivio de tensões foi realizado na empresa parceira unidade Joinville-SC.

Figura 18 - Croqui para pré-usinagem (alívio de tensões).

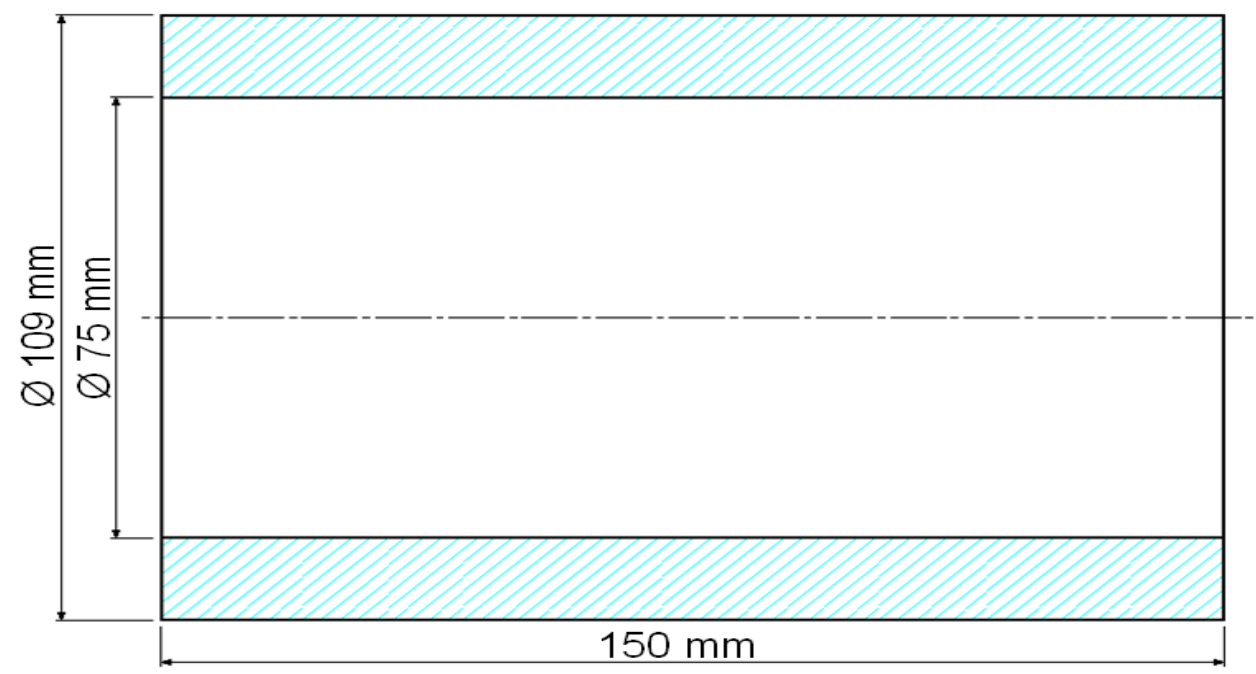

Fonte: o autor, (2016) 


\section{PRÉ-USINAGEM PARA TÊMPERA}

Após o alivio de tensões as peças foram preparadas para o tratamento de tempera a vácuo com sobre metal de 1,0 milímetro. 0 erro de circularidade no perfil de corte foi avaliado antes e pós-tratamento térmico. O tratamento térmico de têmpera e o ensaio HRC foram realizados pelo laboratório homologado.

\section{Torneamento de acabamento}

Para eliminar a deformação nos planos de referência, as peças foram tangenciadas em retífica plana. As principais características determinantes do processo de torneamento final são a instabilidade geométrica e os gradientes de vibração. A fixação convencional em placa universal de três castanhas geraria um esforço tensional em três pontos na peça, tal tensão poderia causar a deformação geométrica. Sendo assim, foi necessário desenvolver um método de fixação para se evitar à deformação. Com todas estas características do processo o gabarito de fixação foi concebido a fim de minimizar as possíveis variáveis, e a opção que melhor atendeu foi à fixação da peça através da rosca (Figura 19).

Figura 19 - Sistema de fixação da peça

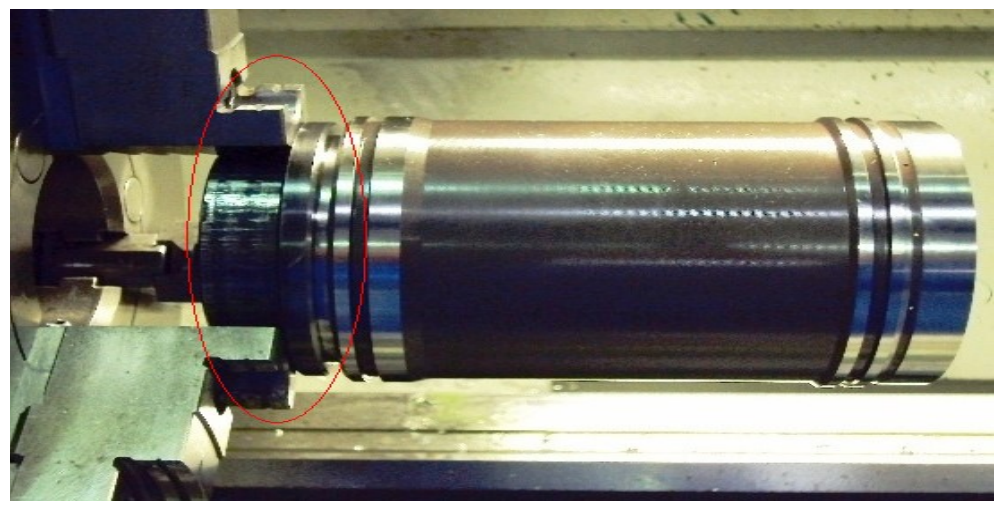

Fonte: o autor, (2016)

O metal definido para a deformação no tratamento térmico de tempera a vácuo foi de 1,0 milímetro, para garantir a estabilidade dimensional no torneamento de acabamento foi necessário à utilização de três ferramentas: desbaste, pré-acabamento e acabamento. Os parâmetros iniciais foram definidos com base na recomendação da SANDVIK COROMANT, 2011.

- Desbaste WNGA 060404 S01030A 7015 - CBN:

$\checkmark \quad a_{\mathrm{p}}=0,10 \mathrm{~mm}(0,07-0,40)$;

$\checkmark \quad(f)=0,10 \mathrm{~mm} / \mathrm{r}(0,05-0,20)$;

$\checkmark \quad v_{c}=215 \mathrm{~m} / \mathrm{min}$.

- Pré-Acabamento CNGA 120404 S01525 6050:

$\checkmark \quad a_{p}=0,1 \mathrm{~mm}(0,1-0,5)$;

$\checkmark \quad(f)=0,1 \mathrm{~mm} / \mathrm{r}(0,05-0,2)$;

$\checkmark \quad v_{c}=160 \mathrm{~m} / \mathrm{min}$ 
- $\quad$ Acabamento TPGN 160304 T01020 650:

$\checkmark \quad a_{\mathrm{p}}=1,6 \mathrm{~mm}(0,1-4,8)$;

$\checkmark \quad(f)=0,07 \mathrm{~mm} / \mathrm{r}(0,05-0,12)$;

$\checkmark \quad v_{c}=120 \mathrm{~m} / \mathrm{min}$.

Devido à instabilidade de corte provocado pela geometria da peça, os parâmetros preliminares utilizados causaram vibração ocasionando a quebra da ferramenta. Para minimizar os efeitos que geraram os gradientes de vibração as velocidades de corte foram reduzidas em aproximadamente $30 \%$.

\section{Retificação cilíndrica}

A retificação cilíndrica seguiu o processo convencional no perfil externo, com a fixação em placa magnética e retificação com rebolo de Carboneto de Silício $\mathrm{SiC}$.

\section{RESULTADOS DO EXPERIMENTO PILOTO}

As peças apresentaram dureza superficial de $60 \mathrm{HRC}$. Devido à dureza, o custo de aplicação do inserto de CBN se justifica, no desbaste foi utilizado o inserto WNGA 060404 S01030A 7015. Os parâmetros de corte utilizados estão demonstrados na Tabela 1.

Tabela 1 - Parâmetros de usinagem de desbaste

\begin{tabular}{lcc} 
Processo & Interno & Externo \\
Profundidade de corte $\left(\mathrm{a}_{\mathrm{p}}\right)_{[\mathrm{mm}]}$ & 0,1 & 0,3 \\
Avanço $(f)[\mathrm{mm} / \mathrm{r}]$ & 0,25 & 0,2 \\
Velocidade de corte $\left(\mathrm{v}_{\mathrm{c}}\right)[\mathrm{m} / \mathrm{min}]$ & 120 & 120 \\
\hline
\end{tabular}

Fonte: O autor, (2016)

A maior dificuldade no processo de desbaste foi com relação à geometria da ferramenta, que por tratar-se de ser negativa ocasionou gradientes de vibração. Sendo assim, foi necessária a utilização de avanço de corte acima do recomendado pela Sandvik, por outro lado a profundidade de corte foi utilizada abaixo do recomendado para balancear as forças de corte.

O passe de pré-acabamento foi utilizado para garantir a estabilidade dimensional no acabamento final. No perfil externo foi utilizado o inserto CNGA 120404 S01525 6050 e para o interno, por se tratar de uma ferramenta positiva foi utilizado o inserto TPGN 160304 T01020 650. Os parâmetros estão na Tabela 2.

Tabela 2 - Parâmetros de usinagem de pré-acabamento

\begin{tabular}{lcc} 
Processo & Interno & Externo \\
Profundidade de corte $\left(a_{\mathrm{p}}\right)_{[\mathrm{mm}]}$ & 0,05 & 0,25 \\
Avanço $(f)[\mathrm{mm} / \mathrm{r}]$ & 0,1 & 0,15 \\
Velocidade de corte $\left(\mathrm{v}_{\mathrm{c}}\right)[\mathrm{m} / \mathrm{min}]$ & 80 & 80 \\
\hline
\end{tabular}

Fonte: O autor, (2016) 
O acabamento final foi realizado nos perfis externo e interno com os insertos TPGN e os parâmetros estão descritos na Tabela 3.

Tabela 3 - Parâmetros de usinagem de acabamento final

\begin{tabular}{lcc} 
Processo & Interno & Externo \\
Profundidade de corte $\left(a_{\mathrm{p}}\right)_{[\mathrm{mm}]}$ & 0,05 & 0,05 \\
Avanço $(f)[\mathrm{mm} / \mathrm{r}]$ & 0,1 & 0,1 \\
Velocidade de corte $\left(\mathrm{v}_{\mathrm{c}}\right)[\mathrm{m} / \mathrm{min}]$ & 80 & 80 \\
\hline
\end{tabular}

Fonte: O autor, (2016)

Seria interessante utilizar ferramentas de CBN na operação de acabamento, no entanto, os grandes fornecedores de ferramentas ainda não oferecem esta opção nos insertos considerados de usinagem "leve". Com a geometria positiva, isto proporcionaria uma força de corte menor, minimizando os efeitos dos gradientes de vibrações e melhorando a estabilidade dimensional da peça usinada. O erro de circularidade foi analisado em todos os processos, os resultados médios estão demonstrados na Tabela 4.

Tabela 4 - Erro de circularidade [mm]

$\begin{array}{lccc}\text { Processo } & \text { Nominal } & \text { Medido } & \text { Desvio Padrão } \\ \text { Antes-têmpera } & 0,05 & 0,014 & 0,012 \\ \text { Pós-têmpera } & 0,30 & 0,196 & 0,117 \\ \text { Pós-torneamento final } & 0,02 & 0,009 & 0,010 \\ \text { Pós-acabamento retífica } & 0,02 & 0,011 & 0,012\end{array}$

Fonte: O autor, (2016)

O processo de têmpera a vácuo apresentou estabilidade dimensional caracterizando um erro de circularidade médio de aproximadamente 0,2 milímetros. Tal resultado remete a um sobre metal 0,5 milímetros o que pode otimizar significativamente o tempo de usinagem. O principal resultado está no tempo de usinagem. Em uma amostragem com lote de quinze peças a usinagem convencional levou o tempo total de processamento de 116 horas, já a nova proposta de usinagem conforme item 4.2.2 o tempo total de processamento foi de 45 horas, uma redução de 61\% conforme ilustrado pelo o Gráfico 1.

Gráfico 1 - Comparação tempos de usinagem

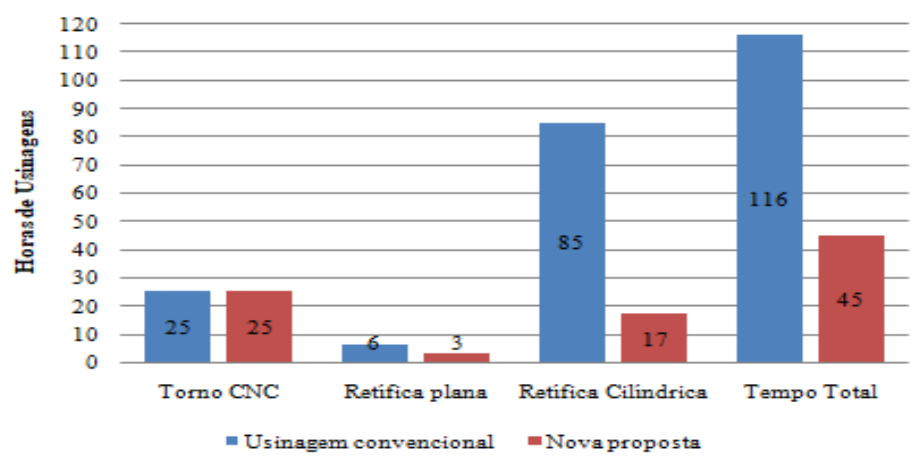

Fonte: o autor, (2016) 
A Tabela 5 ilustra a proporcionalidade dos tempos de processamento relativos a amostragens utilizadas na comparação entre a usinagem convencional e o experimento, onde, para método de usinagem convencional o tempo de usinagem para cada peça foi de 7,7 horas e o para o método proposto item 4.2.2 o tempo para usinagem foi de 3 horas.

Tabela 5 - Tempo total de processamento

\begin{tabular}{lccccc} 
Comparativo & $\begin{array}{c}\text { Qtide } \\
\text { ano }\end{array}$ & $\begin{array}{c}\text { Tempo } \\
\text { processamento } \\
\text { horas }\end{array}$ & $\begin{array}{c}\text { Tempototal } \\
\text { de } \\
\text { processamento } \\
\text { horas }\end{array}$ & $\begin{array}{c}\text { Custo } \\
\text { hora }\end{array}$ & $\begin{array}{c}\text { Custo } \\
\text { Usinagem/hs }\end{array}$ \\
$\begin{array}{l}\text { Usinagem } \\
\text { Convencional } \\
\text { Usinagem } \\
\text { Proposta }\end{array}$ & 100 & 7,7 & 770 & $R \$ 60,00$ & $R \$ 46.200,00$ \\
\hline
\end{tabular}

Fonte: o autor, (2016)

\section{CONSIDERAÇÕES FINAIS}

O estudo da pesquisa focou na avaliação do método atual de usinagem convencional e nos insertos da classe CBN (nitreto cúbico de bório) em peças de geometria estáveis e propor alternativas na redução no tempo de processamento, no custo de usinagem e no erro de circularidade camisa de corte de chapa de polipropileno. Para realização da pesquisa foram produzidos dois lotes com amostragem de 15 peças cada. Um para a usinagem convencional e o outro para experimento com readequações envolvendo doze etapas no processo.

$\mathrm{Na}$ amostragem utilizando o método convencional o tempo de usinagem em torno CNC, retífica plana e cilíndrica totalizaram de 116 horas considerando o valor de $\mathrm{R} \$ 60,00$ hora/máquina de usinagem, o custo apresentado ao final foi de $\mathrm{R} \$ 6.960,00$. Já para o método experimental proposto considerando as 12 novas etapas no processo o tempo para usinagem reduzido para 45 horas. Para este processo de usinagem exigiu-se ferramentas com custo elevado, cerca de $\mathrm{R} \$ 100,00$ a aresta. No processo de usinagem das camisas o custo total de insertos foi $R \$ 435,00$ uma média de $R \$ 25,58 /$ peça. O custo final para esta amostragem experimental foi de $\mathrm{R} \$ 3.851,10$.

Quando comparado os resultados, o experimento proposto apresentou uma redução de $61,2 \%$ no tempo de processamento e economia de $\mathrm{R} \$ 3.108,90$ no custo de usinagem de $\mathrm{R} \$ 3.108,90$, ou seja, redução de $44,6 \%$. Além das reduções de tempo e custo com a usinagem, o erro de circularidade analisados em todos os processos (antes-têmpera; pós têmpera; pós torneamento final e pós-acabamento de retífica) propiciou estabilidade dimensional caracterizando um erro de circularidade médio de $0,057 \mathrm{~mm}$ o que atende as especificações médias de $0,097 \mathrm{~mm}$ determinado na especificação do projeto.

A pesquisa apontou a oportunidade de um novo estudo para poder avaliar a transferência de calor por convecção entre a camisa de corte e camisa interna sem perda no desempenho dos componentes com a diminuição da área interna de usinagem, os quais podem trazer resultados significativos para a "Indústria de Embalagens". 


\title{
The influence on the machining parameters of the hardened matrix in the process and on the production cost of the polypropylene cutting sleeve
}

\begin{abstract}
The conventional cylindrical grinding process is slow and raises the production costs of the most varied components. For this reason, several researches have been carried out on machining in tempered materials. The study focused on the evaluation of the current conventional machining method and on the inserts of the CBN class in stable geometry pieces, in order to propose alternatives in the reduction of processing time, machining cost and circularity error cut shirt made of polypropylene sheet. The methodology used by the experiment on factory floor presented positive results with the pilot project, which proportional to the reduction in the total processing time, presented a reduction in the cost of production as well as maintained the stability in the tolerance of the error of circularity cut sheet jacket of polypropylene.
\end{abstract}

KEYWORDS: Cutting sleeve machining, polypropylene sheet, circularity error. 
AMORIM, Heraldo José de. Estudo da relação entre velocidade de corte, desgaste de ferramenta, rugosidade e forças de usinagem em torneamento com ferramenta de metal duro: Tese de mestrado. PROMEC- escola de Engenharia da Universidade Federal do Rio Grande do Sul - UFRG.

BLACK, J. T.; Introduction to machining processes: metal handbook. Vol. 16: machining. $9^{\circ}$ ed. Washington: ASM Internacional, 1994, 1-4 p.

DINIZ, Anselmo Eduardo; Marcondes, Francisco Carlos; COPPINI, Nivaldo lemos. Tecnologia da usinagem dos materiais: $7^{\circ}$ ed. São Paulo Artiber, 2010 13-187p.

FERRARESI, Dino. Fundamentos da usinagem dos metais. $3^{\circ}$ ed. São Paulo; Edgard, 1977. $16^{\circ}$ reediçao 2013.p. 55.

SANDIVIK COROMANT. Catálogo de Ferramentas de Corte, São Paulo, 2011.

SOUZA, André João de. Aplicação de multi sensores no prognostico da vida da ferramenta de corte em torneamento: Tese de Doutorado. Universidade Federal de Santa $\quad$ Catarina 2004. https://repositorio.ufsc.br/bitstream/handle/123456789/88055/208616.pdf?seq uence $=1$

STEMMER, Caspar Erich. Ferramenta de Corte I: $7^{\circ}$ ed. Florianópolis: UFSC, 2007. 


\section{Lista de referências}

\begin{tabular}{|c|c|}
\hline$Z Y_{f}$ & Ângulo de saída \\
\hline S & Aresta principal de corte \\
\hline$S^{\prime}$ & Aresta secundária de corte \\
\hline ABNT & Associação Brasileira de Normas Técnicas \\
\hline CNC & Comando numérico computadorizado \\
\hline L & Comprimento \\
\hline$x$ & Eixo de referência no plano Cartesiano \\
\hline Z & Eixo de referência no plano Cartesiano \\
\hline SC & Estado de Santa Catarina \\
\hline PR & Estado do Paraná \\
\hline$U$ & Incerteza de medição expandida \\
\hline$\mu \mathrm{m}$ & Micrometros \\
\hline $\mathrm{mm}$ & Milímetros \\
\hline kW & Potência elétrica (Watts) \\
\hline$a_{p}$ & Profundidade de corte \\
\hline CBN & Nitreto Cubico de Boro \\
\hline$f$ & Avanço \\
\hline $\mathrm{HB}$ & Escala de dureza Brinell \\
\hline $\mathrm{HRC}$ & Escala de dureza Rockwell \\
\hline MD & Metal duro \\
\hline $\mathrm{SiC}$ & Carboneto de Silício \\
\hline$v_{c}$ & Velocidade de corte \\
\hline$A_{y}$ & Superfície de saída \\
\hline $\mathrm{A} \alpha$ & Superfície principal de folga \\
\hline$A^{\prime} \alpha$ & Superfície segundaria de folga \\
\hline
\end{tabular}

Recebido: 07 Março 2019

Aprovado: 09 Out. 2020

DOI: 10.3895/gi.v16n1.9755

Como citar:

DA SILVA, T. D.; HIDALGO MARTINS, G. A influência nos parâmetros deu usinagem da matriz endurecida no processo e custo de produção da camisa de corte polipropileno. R. Gest. Industr., Ponta Grossa, v. 16, n.

1, p. 164-185, Jan./Mar. 2020. Disponível em: https://periodicos.utfpr.edu.br/revistagi .

Correspondência:

Gleison Hidalgo Martins

Rua João Gbur, 747 - Bloco A2 AP 41, Bairro Santa Cândida, Curitiba, Paraná, Brasil.

Direito autoral:Este artigo está licenciado sob os termos da Licença Creative Commons-Atribuição 4.0

Internacional.

\section{(c) (i)}

